\title{
Income Disparity among Older Malaysians
}

\author{
Jariah Masud $^{1, *}$ \& Sharifah Azizah Haron $^{1}$ \\ ${ }^{1}$ Institute of Gerontology, Universiti Putra Malaysia, 43400 UPM Serdang, Selangor, \\ Malaysia \\ *Corresponding author: Institute of Gerontology, Universiti Putra Malaysia, 43400 UPM \\ Serdang, Selangor, Malaysia. Tel: 60-3-8947-2754. E-mail: jariah@upm.edu.my
}

Received: November 26, 2013 Accepted: January 24, 2014 Published: May 4, 2014

doi:10.5296/rae.v6i2.5578 URL: http://dx.doi.org/10.5296/rae.v6i2.5578

\begin{abstract}
The aim of this paper is to explore income disparities among older Malaysians. The specific objective is to determine the income disparities among different groups by gender, ethnicity, stratum and region. A total of 2,327 Malaysians, ages 55 to 75, were interviewed for the study. The data show that primary sources of income for older Malaysians, women in particular, were their children. The income disparity among various groups of older Malaysians was rather wide. Men tended to earn higher incomes compared to women. There were income gaps by ethnicity, strata, and region. The income gap among the participants in this study was much wider compared to the general population. The disparity reflected differences in the older persons' ability to meet daily needs, highlighting the need for programs designed specifically to address poverty among older Malaysians.
\end{abstract}

Keywords: income disparity, elderly poverty, Malaysia 


\section{Introduction}

The aging population is of great concern to governments in developing countries as $62 \%$ (313 million) of the world's population aged 65 and over live in emergent countries (Kinsella \& Wan, 2009). Malaysia, which is striving to become a developed nation by 2020, is also projected to become an aged nation by 2035 (Hamid \& Samah, 2006). Rapid national development programs, undertaken since independence, have resulted in increased income, better health, lower fertility, higher educational attainment, and increased life expectancy among the Malaysian population. The country's per-capita income increased from RM16,239 (USD4,510) in 2005 to RM17,698 (USD4,916) in 2008 (EPU, 2009). Eradication of poverty has been the key development agenda of the nation since independence in 1957. Malaysia has been successful in poverty reduction, and the impressive performance of the economy has contributed to a decrease in the overall incidence of targeted poverty from $52.4 \%$ in 1970 to $2.8 \%$ in 2010. Access to education has been one of the key factors enabling the country to reduce poverty. Expansion of educational services has facilitated better education and employment opportunities for Malaysians born after independence in 1957. However, cohort groups born prior to independence experienced limited access to quality education, resulting in limited earning power.

For this study, older Malaysians are defined as those who were born prior to independence in 1957. With increased life expectancy, early mandatory retirement, and limited social security coverage, coupled with changing family structure and lifestyles, today's older Malaysians are vulnerable to poverty. Their economic well-being is dependent upon personal savings, current earning power, and monetary support received from their adult children. This paper focuses on the income disparities among various groups of older Malaysians. This is an important topic for research, not only for Malaysia, but for other developing nations as well. Evidence of poverty among different groups of older Malaysians can serve as evidence to help promote policy initiatives for Malaysia's developmental plans, ensuring that the aged poor are included in efforts to improve the well-being of the overall population. This is particularly important and timely as the country strives to achieve a "zero hard core poor" status in the 10th Malaysia plan.

The specific research objective of this paper was to determine the income inequality (i.e., absolute and relative income) among different groups of older Malaysian populations, categorically analysed by gender, ethnicity, stratum, and region. The analysis focused on the feminization of poverty. More specifically, the research was designed to evaluate the prevalence of the widowed, divorced, and never married older women living in abject poverty. Since Malaysia is a multi-ethnic nation, the income gap among different ethnic groups is of primary concern to the government. This study hopes to shed light on the prevalence of the income gap among diverse ethnic groups. Differences in rural and urban regions are also of concern in Malaysia. A primary outcome associated with this study was to determine if such gaps also exists among older populations living in different regions and locations. 


\section{Review of literature}

Increased life expectancy and changes in employment opportunities, based on formal, versus informal education, make addressing poverty and income equality a top priority in developing countries (Abdel Ghany, 2008). Without comprehensive social security systems in many developing countries, a large number of older citizens will be unable to support themselves. The older Malaysian population is no exception. Lack of employment opportunities among older workers limits their ability to earn income to support themselves. In 2007, 22.7\% of the labor force of the general population of Malaysia was categorized as unpaid family workers with no social safety net. Half of those aged 55-59 and 63.4\% of those aged 60-64 fell into this category. With the mandatory retirement age at 58 years, and limited social security coverage, older workers have to rely upon other sources of income to support themselves throughout their remaining lifespan.

Traditionally, older parents have relied on the support of their adult children. Changing family structure, migration, and increased living costs have slowly eroded this social support system. The modernization and urbanization of the population have led to rapid changes in the Malaysian family structure. This is true in other developing Asian societies as well. Changes in the traditional roles of women, increased educational opportunities for women, delayed ages of marriage, and smaller family sizes are all characteristics that have contributed to the alarming social implications on aging (Rabeiyah \& Hajar, 2003).

The elderly are vulnerable to poverty (Deaton \& Paxson, 1997). Abdel Ghany (2008) reported that population ageing has resulted in increased income inequality in China, Japan, and Korea. The rising income inequality in Asian countries has had, and will continue to have, a significant impact on various dimensions of social life, including higher levels of violent crimes (Hsieh \& Pugh 1993), frequent social conflicts (Alesina \& Perotti 1996), and inhibited economic growth (Aghion, Caroli, \& Garcia-Penalosa, 1999). The effect of income inequality on health and wellness is well documented in a review by Macinko, Shi, Starfield and Wulu, Jr. (2003). In recent years, concerns regarding the large increase in income inequality in China and Korea, resulting from considerable economic growth, has reached alarming proportions (Ravallion \& Chen 1999). While it has been argued that income inequalities, within and between sectors, is likely to have some positive effects on economic growth for individuals with higher incomes who are able to save and invest for the future, it is feared that retaliation against these real and perceived inequalities is possible, especially if those effected believe disparities to be the result of public policy (Abdel Ghany, 2008).

In 1999, Malaysia had the highest income gap in the Asia Pacific region with an income disparity ratio of $11.7 \%$ between the richest $20 \%$ and poorest $20 \%$ of the population (Nair, n.d.). The reason this is important, according to Wilkinson (1997), is that individuals who feel more economically disadvantaged than their peers are also more likely to exhibit poorer health. Cohen, Line, Manuck, Rabin, Heise, \& Kaplan, (1997) concluded that income gaps may lead to illnesses associated with stress and depression, potentially affecting the health and welfare of society at large, not just the impoverished. The link occurs through the disinvestment in human capital and public health, leading to the potential erosion of social 
capital.

It is presumed, in the literature and this paper, that if a person has basic income security he/she is more likely to be economically and socially independent. The economic life-cycle hypothesis suggests that income increases throughout a person's employed years and then declines upon retirement (Johnson, Smeeding, \& Torrey, 2005). In reality, financial security for retirement depends on many factors, including employment, prior savings, investment, and remittances from children. A national survey conducted by the Singapore government in 1991 of people over 55 years old, found that $31.1 \%$ of men and $73.5 \%$ of women had no personal income (Lee, 1998). The same study revealed that over 55\% of those surveyed had no savings and $44.2 \%$ foresaw financial problems during retirement. As these data indicate, older Malaysians need income security in the form of adequate and stable income protection (e.g., minimum wages, wage indexation, comprehensive social security and progressive taxation) to reduce inequality and to supplement those with low incomes (Standing, 2008).

Earnings from employment are a major source of income for most Malaysians. Mandatory age-based retirement, rigid labor laws, regulations, and stereotypes often force those nearing retirement age to stop working. A 2007 survey of Malaysia revealed a decline in labor force participation for workers ages $55-59$ from $53.4 \%$ in 2003 to $49.9 \%$ in 2007. Similar trends were observed among those aged 60-64, whereby labor force participation declined from $42.0 \%$ in 2003 to 35.0\% in 2010 (Department of Statistic, 2010). As in other Asian countries, labor force participation among older women is lower than for men after retirement. This is not always a voluntary choice however. Many workers, both men and women, prefer to work beyond the mandatory retirement age but are forced to contend with human resource personnel who subscribe to stereotypes regarding older workers' declining mental and physical abilities, which are presumed to limit productivity and employability. In 2008, only $6.6 \%$ of Malaysia's workforce was 55 or older, although the mandatory retirement age is currently age 58. Without a comprehensive social security system, it is estimated that only one third of those in the Malaysian labor force will have some level of financial security in their old age. In contrast, in Germany, most of older men (91\%) and older women (82\%) draw pensions from the statutory old-age insurance system (Weidekamp-Maicher \& Naegele, 2007). In the United States, older persons generally retire early for one of three reasons: (a) financial independence, (b) poor health, or (b) policies set forth by social security (Brady, Palermino, Scott, Fernandez, \& Norland, 1987). Even so, the majority of Americans receive some type of state or federal pension benefits.

In summary, retirement preparation among those employed influences income during old age. Moen, Huang, Plassmann, and Dentinger (2006) found in their study that spouses' decision making in the form of retirement planning tends to be positively related to what the respondents' retirement planning behaviour. A study conducted by HSBC (2008) revealed that only a small proportion of people will be prepared for retirement and be completely protected in terms of receiving adequate retirement income. How developing countries deal with the challenges presented by an aging population will continue to be of interest to researchers and policy makers. 


\subsection{Income Sources in Old Age}

Across Asia, there are four major sources of retirement income: (a) families, (b) individuals, (c) government, and (d) employers (HSBC, 2008). In developed economic systems, those with high household income often consider themselves and their employers as the most important sources of retirement income. In contrast, households with lower incomes report the government and their families as most important. The HSBC study reported that in Malaysia, families are a vital source of income for both high and low income earning households, with government support as the second most important resource for low income earning households and the least significant resource for high income households. Changing family structures that includes families having fewer children is a policy concern given that families are a key source of income for older adults. In Malaysia, the average household size declined from 5.2 persons per household in 1980 to 4.6 persons in 2000. The prevalence of extended families is also on the decline, from 58\% in 1991 to $49 \%$ in 2000 (Rabeiyah \& Hajar, 2003). Studies have shown that major sources of income for the aged Malaysian population are remittances from family members, especially children (Chou \& Chow, 2005; Masud, Haron, \& Hamid, T.A, 2008). Lee and Xiao (1998) concluded that familial transfers help to counteract the unequal access to public resources their elders endure. This is evidenced in a study in China whereby adult children gave greater support to their elderly parents if the parents had lower incomes, lower occupational positions, or poor health.

\subsection{Income Inequality}

Income is related to functional capability, physical activity, and to some extent, psychological well-being. Income is also a potential measure of social status for older workers, while functional capability and physical activity have been shown to be very important to the overall health and well-being of older individuals. Along with income, consumption is a key indicator of well-being as it measures the utilization of goods and services rather than income generation. Mollenkopf and Walker (2007) proposed that income be used as a proxy for describing the overall economic resources of a person. Income inequality has been shown to negatively affect purchasing power, which reduces choices available to older populations. Further, economic hardship is known to be a leading cause of depression among older populations in both the West and in Asia (Knesebeck, Luschen, Cockerham, \& Siegrist, 2003; Li 1995). However, it is important to note that while generally true, not all developing countries exhibit these income outcomes. A study conducted in Thailand among retirees revealed that feelings of contentment were observed and may be influenced by the practice of, or belief in, the Buddhist philosophy (Gray, Rukumnuaykit, Kittisuksathit, \& Thongthai, 2008).

Income inequality also has a gender dimension. Spratlin and Holden (2000) concluded that women living alone were worse off economically compared to other groups. These results stemmed from family responsibilities and survivorship issues. Spratlin and Holden highlighted a variety of efforts undertaken by countries to ensure income security among older women living alone.

How much income someone earns may not matter as much as how someone perceives the 
adequacy of his or her income. The subjective evaluation of one's income reflects their level of satisfaction towards income. George, Cutler, Weinert \& Lawton (1992) pointed out that the integration of subjective measures (e.g., financial satisfaction and subjective well-being) and objective income measures may provide useful insight for policy makers when approaching the issue of income adequacy both pre- and post-retirement. It is essential for research to incorporate detailed, objective measures of income (e.g., equivalence scales that take into account family size, age, and household composition) in order to gain an understanding of the true relationship between income, financial satisfaction, and subjective well-being (Hsieh, 2004).

Hansen, Slagsvold, and Moum (2008) noted that older persons earn substantially less than middle aged persons. One would expect an inverse relationship between age and financial satisfaction; however, much of the literature suggests otherwise. Findings from the first representative studies of social indicator research showed that older respondents were, on average, more satisfied with their material situation than their younger counterparts (Campbell et al., 1976). High financial satisfaction among older persons is primarily a result of accommodative strategies such as re-scaling goals and adjusting aspirations to the present financial realities. George, Cutler, Weinert \& Lawton (1992) used data from a meta-analysis to point out that in the United States between 1960 and 1990, there were exceptionally high satisfaction levels among older people. Earlier George, Okun \& Landerman, (1985) concluded that subjective quality of life, particularly at a more mature ages, was determined less and less by the direct influence of income. This paper adds to the existing literature by examining income adequacy perceptions among older Malaysians.

\section{Methodology}

Data used in this analysis were obtained from the "Economic and Financial Aspects of Ageing” survey conducted throughout Malaysia in 2004 and 2005. The survey was financed by the Ministry of Science, Technology and Innovations. The list of districts with population ages 55-75 were used as the sampling frame. The districts with the highest number of older residents were ranked and systematically selected. Data were collected from 72 districts through personal interviews administered by trained enumerators. A questionnaire in Malay language was translated into English, Mandarin, and Tamil to facilitate interviews with the respective ethnic groups. For Sabah and Sarawak (i.e., Malaysian districts), local people were employed to conduct the interviews. Equal number of males and females were targeted as samples.

\subsection{Variables}

This paper utilizes data collected specifically on income and perceived adequacy of income. Data on income were obtained by asking respondents to indicate: if they have ever received money from 11 identified sources and the frequency and estimated amount of money received. The 11 sources were then divided into three categories: (a) earned income (e.g., salary, pension, income from agriculture and business); (b) investment related income (e.g., rent, 
interest, dividend and bonuses); and (c) social income (e.g., remittance from sons, daughters and relatives). Income inequality was measured by comparing mean and standard deviation, income quintile (Lorenz Curve and Gini Ratio). The income gap between the highest and lowest $20 \%$ quintile, as well as the gap between selected groups, was also calculated. Respondents were also asked to indicate how they perceived the adequacy of their income to be: (a) not adequate, (b) adequate for basic needs, (c) adequate for most things but not all, (d) adequate for all things needed, and (e) adequate for all needed and enough to save.

\section{Results}

A total of 2,327 Malaysians, ages 55 to 75, were interviewed for the study. The sample included 51\% males, 67\% married, 43\% rural residence, 56\% Malays, 23\% Chinese, 7\% Indians, and 15\% other (e.g., various ethnic groups in Sabah and Sarawak). The majority of respondents (79\%) were from Peninsular Malaysia, with 11\% from Sabah, and 10\% from Sarawak. More than $80 \%$ of the respondents had no formal education beyond primary school.

\subsection{Sources of Income}

The mean results from the three component sources of income received by the respondents, categorized by sex, ethnicity, region, and stratum, are shown in table1. One hundred eighty-three $(7.9 \%)$ respondents reported having no sources of income, two thirds of which were women. Table 1 shows the percentage of respondents receiving income in three categories: (a) earned income, (b) investment related income, and (c) social income. The findings revealed a high proportion of older persons (70.7\%) in Malaysia received money from social income sources (i.e., from children and relatives), irrespective of gender, ethnicity, stratum, or region. Almost half (48.3\%), received income from working, and only $11 \%$ received investment related income. These findings seem to indicate that older persons in Malaysia are largely dependent on support from family and working. Income received from children reflects strong traditional values of filial piety or filial obligation that is still prevalent in this region. These findings support Chow's (2000) conclusions that showed 60\% of the elderly parents in Hong Kong were supported financially by their adult children. 
Table 1. Percentage of respondents receiving monthly income from three income components by sex, ethnicity, region, and stratum (per month)

\begin{tabular}{clllll}
\hline & & $\begin{array}{l}\text { Earned } \\
\text { Income }\end{array}$ & $\begin{array}{l}\text { Investment } \\
\text { income }\end{array}$ & $\begin{array}{l}\text { Social } \\
\text { income }\end{array}$ & $\begin{array}{l}\text { Total } \\
\text { Income }\end{array}$ \\
\hline Sex & Male & 67.66 & 13.41 & 63.50 & 95.16 \\
& Female & 30.46 & 8.53 & 78.15 & 89.03 \\
Ethnicity & Malay & 54.71 & 10.19 & 67.44 & 91.74 \\
& Chinese & 39.39 & 7.84 & 71.13 & 92.35 \\
& Indian & 33.95 & 8.02 & 69.75 & 88.27 \\
& Others & 51.16 & 20.23 & 82.95 & 95.09 \\
Region & Peninsular & 48.89 & 9.02 & 68.17 & 91.20 \\
& Sabah & 48.22 & 17.79 & 81.42 & 96.44 \\
& Sarawak & 53.65 & 19.31 & 79.40 & 94.85 \\
Stratum & Rural & 52.35 & 10.59 & 67.23 & 90.61 \\
& Urban & 46.98 & 11.31 & 73.38 & 93.29 \\
& & 49.30 & 11.00 & 70.70 & 92.10 \\
\hline
\end{tabular}

The comparison across the three categories of income, by gender, revealed a sharp differentiation in the sources of income received by men versus women. The proportion of older men receiving earned income was almost double than that of women. The percentage of women with earned income was smaller due to the fact that the majority of the surveyed women did not work during their primary earning years. The female labor force in Malaysia has been below 50\% for many years (Department of Statistics, 2011). A similar trend was observed in association with investment related income. In contrast, significantly higher proportions of older women reported receiving social income compared to men.

When analyzed by ethnicity, a higher proportion of Malays, compared to other ethnic groups, reported receiving income from earnings primarily in farming and self-employment. The highest proportion of participants in the "other" category reported receiving income from social sources. The traditional support from families in Sabah and Sarawak is much stronger compared to Peninsular Malaysia, with the main economic activities of the respondents being agriculture. A higher proportion of Chinese in this study reported receiving money from their children. This finding matches results from other studies (e.g., Chow, 2000). Further analysis showed that the Chinese elderly received money from their children on a monthly basis whereas other ethnic groups tended to received money on an irregular basis and in smaller amounts. Regionally, relatively higher proportions of older persons from Sarawak reported receiving income from work and investment while higher proportions of those in Sabah reported receiving money from children (Note: Sarawak and Sabah are heavily dependent on agriculture).

Table 2 shows the mean yearly income of respondents in three income categories: (a) earned income, (b) investments, and (c) social income. Data in the table indicate that mean income received from earning was the highest, followed by income received from investments, although the number of respondents who fell into this category was small. Men reported 
receiving higher earned income. A greater proportion of women reported receiving money from social income. Children appeared to be the primary source of income contribution for older women, although the amount received tended to be small and irregular. Income disparities between regions is a major development issues for the Malaysian government. Of the three regions, mean income received by older Sarawakians was the lowest.

Table 2. Mean yearly income in the three income categories by selected background

\begin{tabular}{lcccccccccccc}
\hline & \multicolumn{3}{c}{ Earned Income } & \multicolumn{4}{c}{ Investment Income } & \multicolumn{3}{c}{ Social Income } & \multicolumn{3}{c}{ Total Income } \\
\hline & Mean & $\mathrm{n}$ & s.d. & Mean & $\mathrm{n}$ & s.d. & Mean & $\mathrm{n}$ & s.d. & Mean & $\mathrm{n}$ & s.d. \\
\hline Male & 9732.9 & 797 & 13425.7 & 3968.63 & 158 & 6283.5 & 2509.4 & 748 & 3772.19 & 9153.68 & 1121 & 12941.70 \\
Female & 4538.8 & 350 & 5471.87 & 2864.84 & 98 & 3783.5 & 2949.2 & 398 & 6045.79 & 4416.22 & 1023 & 7123.69 \\
Peninsula & 8301.9 & 900 & 11890.9 & 3717.50 & 166 & 5209.3 & 2634.4 & 125 & 3846.66 & 6786.86 & 1679 & 10374.89 \\
Sabah & 8511.5 & 122 & 13338.8 & 4534.20 & 45 & 7813.9 & 3662.7 & 206 & 5720.02 & 8184.34 & 244 & 12649.45 \\
Sarawak & 6684.2 & 125 & 9647.51 & 1925.64 & 45 & 2737.9 & 2512.2 & 185 & 9899.98 & 6275.79 & 221 & 11955.41 \\
Malay & 7165.7 & 709 & 10575.2 & 3332.73 & 132 & 4940.0 & 2082.8 & 374 & 3013.62 & 6174.02 & 1189 & 9694.52 \\
Chinese & 13221. & 206 & 15732.0 & 5981.71 & 41 & 8663.4 & 4150.4 & 372 & 5051.04 & 9343.28 & 183 & 12930.54 \\
Indian & 10599. & 55 & 13072.4 & 4359.85 & 13 & 3156.7 & 3123.1 & 113 & 3963.62 & 6941.15 & 143 & 9910.58 \\
Others & 5415.9 & 177 & 8825.08 & 2370.70 & 70 & 3783.5 & 2816.0 & 287 & 9007.79 & 5874.69 & 329 & 11235.90 \\
Rural & 6079.4 & 524 & 10399.8 & 2420.28 & 106 & 4528.7 & 1613.7 & 673 & 2399.96 & 4992.57 & 707 & 9054.08 \\
Urban & 9887.7 & 623 & 12666.5 & 4341.65 & 150 & 5951.8 & 3534.9 & 973 & 6265.41 & 8286.83 & 1237 & 11779.55 \\
\hline
\end{tabular}

$\mathrm{s} . \mathrm{d}=$ standard deviation

\subsection{Income Disparity}

The mean income for each income quintile for different groups is shown in table 3 . The lowest 20\% income quintile represents Sarawak, which reported the lowest mean income (RM141.93 (USD47.3)). Meanwhile, men reported highest mean income (RM249.71 (USD83.2)) within the lowest 20\% quintile. Those from Sabah reported the highest mean income among the top 20\% group. Table 3 also shows the income gap between the highest $20 \%$ income quintile and lowest $20 \%$ income quintile. The highest gap was observed among the elderly in Sarawak, while the lowest was among ethnic Malay. The highest $20 \%$ quintile mean income in Sarawak was 158 times compared to the lowest 20\% quintile. The table shows that the income gap is relatively wide for all groups. 


\section{Ml Macrothink}

Table 3. Mean income by income quintile and selected background

\begin{tabular}{|c|c|c|c|c|c|c|c|}
\hline & & Lowest 20\% & $40 \%$ & $60 \%$ & $80 \%$ & Highest 20\% & Gap L-H* \\
\hline \multirow[t]{2}{*}{ Sex } & Male & 249.71 & 1525 & 4019.39 & 7174.47 & 22500.58 & 90 \\
\hline & Female & 211.04 & 1607 & 3846.70 & 7114.10 & 18644.02 & 88 \\
\hline \multirow[t]{4}{*}{ Ethnic } & Malay & 238.66 & 1511 & 3997.59 & 7184.27 & 20062.35 & 84 \\
\hline & Chinese & 248.13 & 1692 & 3846.25 & 7134.88 & 23347.04 & 94 \\
\hline & Indian & 193.85 & 1821 & 3885.56 & 6790.40 & 20588.36 & 106 \\
\hline & Others & 185.91 & 1479 & 3789.19 & 7149.57 & 23127.06 & 124 \\
\hline \multirow[t]{3}{*}{ Region } & Peninsular & 239.99 & 1584 & 3956.66 & 7102.35 & 21017.39 & 88 \\
\hline & Sabah & 222.07 & 1443 & 3859.63 & 7292.91 & 23954.97 & 108 \\
\hline & Sarawak & 141.93 & 1605 & 3746.16 & 7392.14 & 22404.87 & 158 \\
\hline \multirow[t]{2}{*}{ Stratum } & Rural & 210.25 & 1509 & 3911.38 & 7072.14 & 19260.98 & 92 \\
\hline & Urban & 246.68 & 1617 & 3941.79 & 7203.58 & 22405.50 & 91 \\
\hline
\end{tabular}

$\mathrm{L}=\mathrm{H}: *$ value Highest $20 \%$ divide by value Lowest $20 \%$ quintile

Poverty rates among the participants in this study were computed using the official Poverty Line Income by region (i.e., Peninsular = RM661 (USD220), Sabah = RM888 (USD296) and Sarawak = RM765 (USD255) (Economic Planning Unit, 2005). The incidence of poverty by selected background is shown in table 4. The data revealed that the incidence of poverty, using income received as a measurement, was very high $(70.7 \%)$ compared to the national poverty data for the general population. The highest incidences of poverty were among older women at $83.8 \%$, compared to the other groups.

Less than half of the men surveyed (40.7\%) reported earning income above the national poverty line. As was the case nationally, poverty among the elderly in rural areas is much higher than in urban areas. More than three quarters of older persons in the rural areas reported earning income below the poverty line, with higher percentages of the Sarawak population being in poverty compared to Peninsular Malaysia and Sabah populations. Since Sarawak is predominantly an agriculture based economy, such findings are expected. Under the 9th Five-Year Malaysia Plan, the government had appropriated large sums of the budgetary allocation to eradicate poverty in Sarawak and Sabah, while continuing the effort to overcome poverty problems in Peninsular Malaysia. While marginally effective, more attention is needed to achieve the goal. 
Table 4. Poverty Rate of Older Persons Using Poverty Line Income by Selected Background

\begin{tabular}{llllll}
\hline \multirow{2}{*}{ Sex } & & \multicolumn{2}{c}{ Poor } & \multicolumn{2}{c}{ Non Poor } \\
\cline { 3 - 6 } & Male & 661 & 59.34 & 453 & 40.66 \\
Stratum & Female & 816 & 83.78 & 158 & 16.22 \\
& Rural & 681 & 77.47 & 198 & 22.53 \\
\multirow{3}{*}{ Region } & Urban & 796 & 65.84 & 413 & 34.16 \\
& Peninsular & 1134 & 69.61 & 495 & 30.39 \\
& Sabah & 175 & 72.92 & 65 & 27.08 \\
Ethnic & Sarawak & 168 & 76.71 & 51 & 23.29 \\
& Malay & 826 & 71.52 & 329 & 28.48 \\
& Chinese & 290 & 61.70 & 180 & 38.30 \\
& Indian & 100 & 71.94 & 39 & 28.06 \\
Total & Others & 261 & 80.56 & 63 & 19.44 \\
& & 1477 & 70.74 & 611 & 29.26 \\
\hline
\end{tabular}

Table 5 shows the income disparity ratio between groups. The largest disparity was between men and women, followed by the residential category of local. Men reported receiving twice as much income compared to women. Higher levels of income for men are clearly associated with enhanced levels of educational attainment received by Malaysian men. Traditionally, advanced education has not been as widely available to Malaysian women. This is a clear advantage for men in their ability to earn more and save for retirement.

Table 5. Income Disparity Ratio

\begin{tabular}{lll}
\hline Background & Comparison & Ratio \\
\hline Sex & Male-Female & 2.1 \\
Ethnicity & Malay-Chinese & 0.7 \\
& Malay-Indian & 0.9 \\
& Malay- Others & 1.1 \\
& Chinese Indian & 1.3 \\
& Chinese- others & 1.6 \\
Region & Indian-Others & 1.2 \\
& Peninsular- Sabah & 0.8 \\
& Peninsular-Sarawak & 1.1 \\
Strata & Sabah-Sarawak & 1.3 \\
\hline
\end{tabular}

Within Malaysia, the Chinese report higher earning and income levels compared to other ethnic groups. While the Chinese have historically been involved in trading, Malays and others have relied upon small-scale farming activities. Indians were more involved as estate workers. The impact of the traditional division by specialization has an economic impact on the earning potential of the population as a whole.

Figure 1 shows the Lorenz curve of respondents' total income. The calculated Gini Coefficient in this study was 0.56, which compares to the National Gini Ratio in 2004 of 0.46. Data revealed that income disparities among the elderly are much larger compared to national 
outcomes. The income gap reflects older persons' limited access to financial resources to meet basic needs. Those with limited financial resources may find it difficult to meet their basic needs or they may have to depend on others for support during their old age. With fewer children and increased costs of living, the elderly cannot depend on their children to support them financially. Without financial resource, the elderly may have a reduced standard of living.

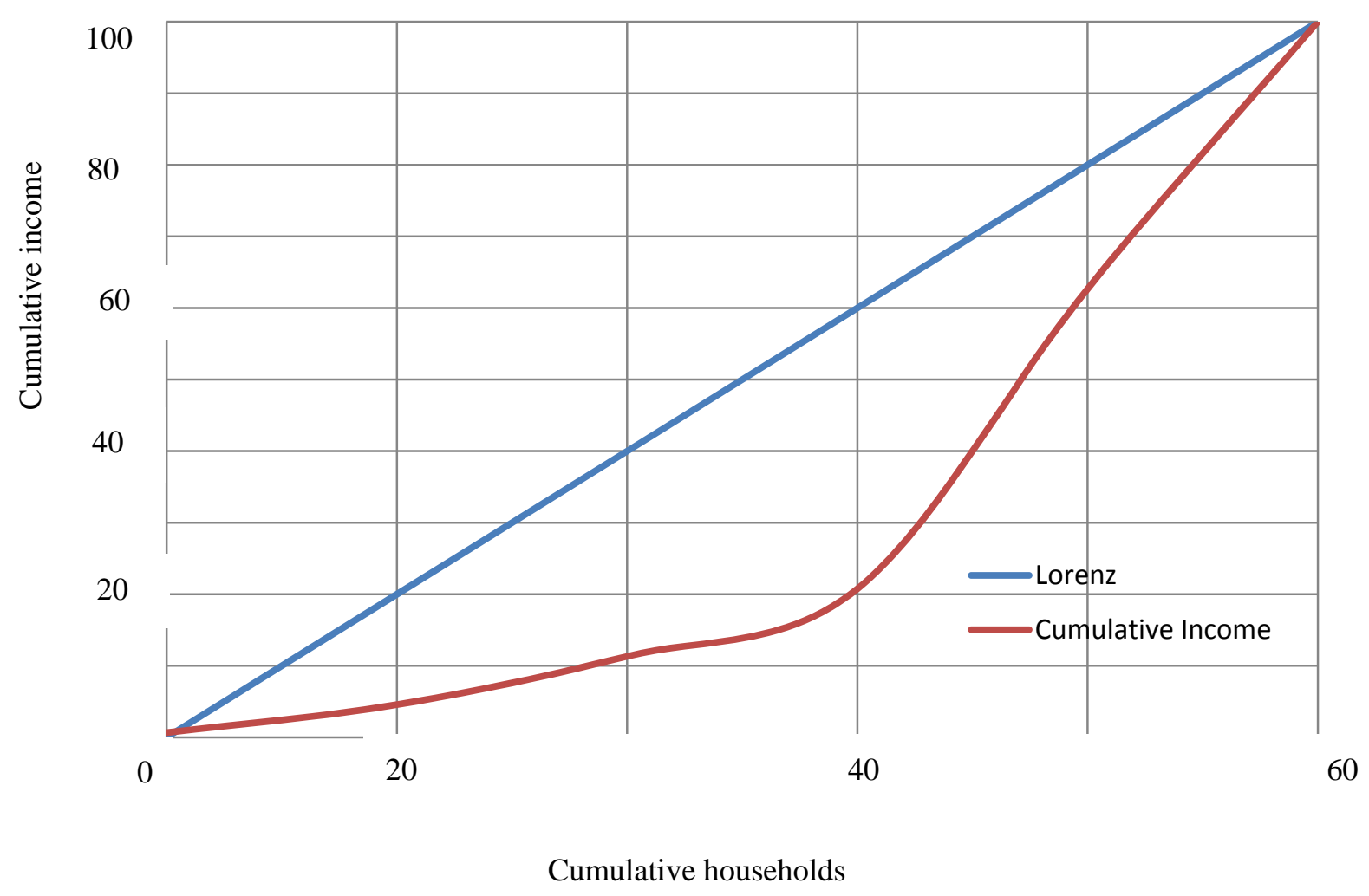

Figure 1. Lorenz Curve for Total Income of Older Persons

\section{Conclusion}

Using income and age as measures of poverty, the majority of the elderly in this study met the poverty criteria. The proportion of poor women was much higher than for men due to the fact that women had limited sources of income compared to men. The data also show there were significant differences in sources of income based on gender, ethnicity, stratum, and region. Older women, Malays who reside in the rural areas, as well as those who live in Sabah and Sarawak, tend to have lower mean incomes compared to the other groups. The trend is similar to the income distribution patterns of the country, with income disparities among the elderly much wider, compared to the average household.

It is widely known that income determines purchasing power and financial independence. Efforts to ensure that the elderly have access to minimum financial security will be necessary in Malaysia and other developing countries. Since Malaysia is projected to become an aged nation by 2030, support systems need to be put in place to ensure the well-being of the elderly. 
The newly revised government Policy for the Elderly and plan of action reflect their commitment to ensure the well-being of the elderly population in Malaysia.

\section{Acknowledgement}

The research is financed by the Ministry of Science, Technology and Innovation (MOSTI) Malaysia. Thanks to the anonymous reviewers for their invaluable comments and Professor Dr John Grable, University of Kansas, Kansas USA for his invaluable insights on the earlier manuscript.

\section{References}

Abdel-Ghany, M. (2008). Problematic Progress in Asia: Growing Older and Apart. Journal of Family Economic Issues, 29, 549-569. http://dx.doi.org/10.1007/s10834-008-9129-4

Aghion, P., Caroli, E., \& Garcia-Penalosa, C. (1999). Inequality and economic growth: The perspective of the new growth theories. Journal of Economic Literature, 37, 1615-1660.

Alesina, A., \& Perotti, R. (1996). Income distribution, political instability and investment. European Economic Review, 40, 1028-1203.

Apt, N. A. (2002). Ageing and the changing role of the family and the community: An African perspective. International Social Security Review, 55, 39-47. http://dx.doi.org/10.1111/1468-246X.00113

Arendt, J. N. (2005). Income and “outcomes” for elderly: Do the poor have a poorer life? Social Indicators Research, 70, 327-347.

Brady, E. M., Palermino, P., Scott, D., Fernandez, R., \& Norland, S. (1987). Barriers to work among the elderly: A Connecticut study. Journal of Applied Gerontology, 6, 415-428. http://dx.doi.org/10.1177/073346488700600405

Campbell, A., Converse, P. E., \& Rogers, W. L. (1976). The Quality of American Life. Ann Arbor, MI: Institute for Social Research.

Caraher, K. (2000). Issues in income provision for the elderly in Malaysia. The year 2000 International Research Conference on Social Security, Helsinki, 25-27 September.

Chan, Y. F. B. (2005). Financial Wellbeing of Older Malaysians, Unpublished Master's Thesis, Universiti Putra Malaysia, Serdang Selangor.

Chou, K. L., \& Chow, N. W. S. (2005). Income inequality among older adults in Hong Kong: An analysis of change from 1981 to 2001. Journal of Applied Gerontology, 24, 388-403. http://dx.doi.org/10.1177/0733464805278647

Cohen, S., Line, S., Manuck, S., Rabin, B., Heise, E., \& Kaplan, J. (1997). Chronic social stress, social status, and susceptibility to upper respiratory infections in nonhuman 
primates. Psychosomatic Medicine, 59, 213-221.

Deaton, A., \& Paxson, C. (1997). Poverty Among Children and the Elderly in Developing Countries. Paper 179 Princeton, Woodrow Wilson School - Development Studies.

Department of Statistics (2010). Labor Force Survey 2010. Department of Statistics Malaysia, Putrajaya, Malaysia.

Economic Planning Unit. (2001). Eight Malaysia Plan 2001-2005. Kuala Lumpur: Percetakan Nasional Malaysia Bhd.

Economic Planning Unit. (2006). Ninth Malaysia Plan 2006-2010. Kuala Lumpur: Percetakan Nasional Malaysia Bhd.

George, L. K., Cutler, N. E., Weinert, Gregg. D. W., \& Lawton, M. P. (1992). Economic status and subjective well-being: A review of the literature and an agenda for future research. Aging, money, and life satisfaction: Aspects of Financial Gerontology, 69-99. New York, NY, US: Springer Publishing Co, xiii, 189 pp.

George, L.K., Okun, M.A., \& Landerman, R. (1985). Age as a moderator of the determinants of life satisfaction. Research on Aging, 7, 209-233. http://dx.doi.org/10.1177/0164027585007002004

Gray, R. S., Rukumnuaykit, P., Kittisuksathit, S., \& Thongthai, V. (2008). Inner happiness among Thai elderly. Journal Cross Cultural Gerontology, 23, 211-224. http://dx.doi.org/10.1007/s10823-008-9065-7.

Hamid, T. A., \& Samah, A. A. (2006). Demography of ageing and community care of the elderly in Malaysia: Issues and challenges (pp 169-189). In Wong Yut Lin and Tey Nai Peng (Eds). Our People our Future: Malaysian Population in Perspective. Kuala Lumpur, University Malaya Press.

Hansen, T., Slagsvold, B., \& Torbjørn, M. (2008). Financial satisfaction in old age: A satisfaction paradox or a result of accumulated wealth? Social Indicator Research, 89, 323-347. http://dx.doi.org/10.1007/s11205-007-9234-z.

Help Age International (HAI) (1999). The Ageing and Development report: a summarypoverty, Independence and the world's older people. Help Age International.

HSBC. (2008). The Future of Retirement. www.hsbc.com/retirement. (Accessed January 15, 2009).

Lee, W. K. M. (1998). Income protection and the elderly: An examination of social security policy in Singapore. Journal of Cross-Cultural Gerontology, 13, 291-307. http://dx.doi.org/10.1023/A:1006541410391

Lee, Y. J., \& Xiao, Z. (1998). Children's support for elderly parents in urban and rural China: Results from a national survey. Journal of Cross-Cultural Gerontology, 13, 39-62. http://dx.doi.org/10.1023/A:1006591608724 
Li, L. (1995). Subjective well-being of Chinese urban elderly. International Review of Modern Sociology, 25, 17-26. http://www.jstor.org/stable/41421083

Macinko J.A., Shi L., Starfield B.and Wulu, J. T. Jr. (2003) Income Inequality and Health: A Critical Review of the Literature. Medical Care Research and Review; 60, 407-452 http://dx.doi.org/10.1177/1077558703257169

Masud, J., Haron, S. A., \& Hamid, T.A. (2008). Perceived income adequacy and health status among older persons in Malaysia. Asia Pacific Journal of Public Health, 18, 2-8.

Moen, P., Huang, Q., Plassmann, V., \& Dentinger, E. (2006). Deciding the future: Do dual-earner couples plan together for retirement? American Behavioral Scientist, 49, 1422-1443. http://dx.doi.org/10.1177/0002764206286563

Nair, S. (n.d). Poverty in the new millennium - Challenges for Malaysia. Retrieved January 10, 2010 from www.devnet.org.nz/conf/Papers/nair.pdf

Quinn, F. J. (1985). The Economic status of the elderly: Beware of the mean. Paper presented at the nineteenth conference of the international Association for research on income and wealth. August, 1985. Noordwijkerhout, the Netherlands.

Rabieyah, M., \& Hajar, T. (2003). Socio-economic characteristics of the elderly in Malaysia. 21st Population Census Conference, Kyoto, Japan 19 - 21 November.

Ravallion, Martin and Chen, Shaohua (1999) When Economic Reform is Faster Then Statistical Reform: Measuring and Explaining Income Inequality in Rural China. Oxford Bulletin of Economics and Statistics, 61(1), 33-56, http://dx.doi.org/10.1111/1468-0084.00115

Smith, P. J. (1997). The changing economic circumstances of the elderly: Income, wealth, and Social Security. Policy brief No. 8/1997.

Spratlin, J., \& Holden, K. C. (2000). Women and economic security in retirement: Implications for social security reform. Journal of Family and Economic Issues, 21, 37-63. http://dx.doi.org/10.1023/A:1009427530441

Standing, G. (2008). Economic insecurity and global casualisation: Threat or promise? Social Indicator Research, 88, 15-30. http://dx.doi.org/10.1007/s11205-007-9202-7

Stoller, M. A., \& Stoller, E. P. (2003). Perceived income adequacy among elderly retirees. The Journal of Applied Gerontology, 22, 230-251. http://dx.doi.org/10.1177/0733464803022002004

Wang, H. (1991). Income and expenditure inequality of elderly households: An analysis using the Gini Coefficient. Family Economics and Management Biennial, 1, 179-184.

Weidekamp-Maicher, M., \& Naegele, G. (2007). Economic resources and subjective well-being in old age. In H. Mollenkopf and A. Walker (eds.), Quality of Life in Old Age, 65-84. New York: Springer. 


\section{Macrothink}

Research in Applied Economics

ISSN 1948-5433

2014, Vol. 6, No. 2

Wilkinson, Richard G. (1997). Health inequalities: Relative or absolute material standards? British Medical Journal, 314, 591-595.

\section{Copyright Disclaimer}

Copyright reserved by the author(s).

This article is an open-access article distributed under the terms and conditions of the Creative Commons Attribution license (http://creativecommons.org/licenses/by/3.0/). 